\title{
Is it possible to perform gastric endoscopic submucosal dissection without discontinuation of a single antiplatelet of thienopyridine derivatives?
}

\section{(이요 $\odot$}

\author{
Authors \\ Satoshi Ono ${ }^{1}$, Masahiro Myojo르. Hideaki Harada ${ }^{3}$, Kunihiro Tsuji ${ }^{4}$, Daisuke Murakami ${ }^{3}$, Satoshi Suehiro ${ }^{3}$, Hisashi \\ Doyama $^{4}$, Jiro Ando², Itaru Saito', Mitsuhiro Fujishiro ${ }^{1,5}$, Issei Komuro², Kazuhiko Koike
}

Institutions

1 Department of Gastroenterology, Graduate School of Medicine, The University of Tokyo, Bunkyo-ku, Tokyo, Japan

2 Department of Cardiovascular Medicine, Graduate School of Medicine, The University of Tokyo, Bunkyo-ku, Tokyo, Japan

3 Department of Gastroenterology, New Tokyo Hospital, Chiba, Japan

4 Department of Gastroenterology, Ishikawa Prefectural Central Hospital, Ishikawa, Japan

5 Department of Endoscopy and Endoscopic Surgery, Graduate School of Medicine, The University of Tokyo, Tokyo, Japan

submitted 4.3.2017

accepted after revision 14.6.2017

Bibliography

DOI https://doi.org/10.1055/s-0043-116381 |

Endoscopy International Open 2017; 05: E943-E949

(c) Georg Thieme Verlag KG Stuttgart · New York

ISSN 2364-3722

Corresponding author

Satoshi Ono, MD, PhD, Department of Gastroenterology, Graduate School of Medicine, The University of Tokyo,

7-3-1 Hongo, Bunkyo-ku, Tokyo 113-8655, Japan

Fax: +81-3-5800-8806

satoshi-tky@umin.ac.jp

\section{ABSTRACT}

Background and study aims Combined use of thienopyridine derivatives and other antithrombotic agents is reported to be a risk factor for postoperative bleeding after gastric endoscopic submucosal dissection (ESD). However, risk associated with a single thienopyridine derivative has not been evaluated. In this study, we aimed to evaluate bleeding risks of gastric ESD without discontinuation of a single thienopyridine derivative agent.

Patients and methods This multicenter, prospective, observational cohort study included patients who had undergone implantation of a coronary artery stent and who were taking a combination of aspirin antiplatelet therapy and a thienopyridine derivative agent. Enrolled patients discontinued aspirin and underwent gastric ESD without the discontinuation of a single thienopyridine derivative agent. The primary endpoint was the major bleeding complication rate after gastric ESD.

Results Eleven patients were enrolled in this study from April 2015 to November 2016 after written informed consent was obtained. Among them, 1 patient, who had undergone surgery for a primary cardiac tumor before ESD, was excluded from the study. Ten patients underwent gastric ESD for neoplasms. En-bloc resections were achieved in all cases without intraoperative bleeding complications. Two patients experienced postoperative bleeding although neither case required a blood transfusion ( $95 \% \mathrm{Cl} 2.5-55.6 \%)$. Conclusion En-bloc resections were possible although the postoperative bleeding rate tended to be higher in gastric ESD without discontinuation of a single thienopyridine derivative agent. Additional preventive measures are mandatory to carry out safe gastric ESD in such settings.

\section{Introduction}

Endoscopic resections (ERs) are now accepted as established and reliable therapies for gastrointestinal neoplasms. One such therapy is endoscopic submucosal dissection (ESD) that enables en-bloc resections that are preferable for comprehensive histopathologic assessment of resected specimens [1-3]. Thus, ERs including ESD play important roles in clinical daily practice of treating gastrointestinal disease, although risk of bleeding is still a major problem. Gastric ESD is reported to be associated with a $5 \%$ postoperative bleeding rate $[4,5]$. Use of antiplatelet agents increases risk of postoperative bleeding 


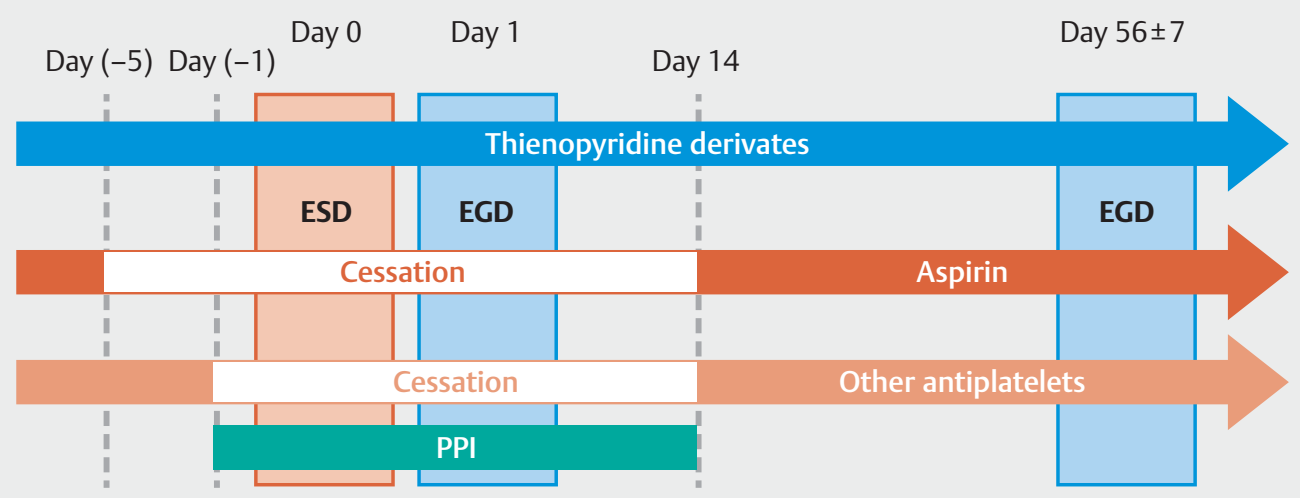

Fig. 1 Schedule of study participants.

after gastric ESD, particularly in patients administered a combination of antiplatelet agents [4-7].

On the other hand, antiplatelet agents are mandatory for prophylactic treatment of a thromboembolic event including cardiovascular disease $[8,9]$. In particular, a combination of aspirin and thienopyridine derivatives [dual antiplatelet therapy (DAPT)] is a key treatment for a period of time after implantation of a coronary stent [10]. After a period on DAPT, it is common to continue on a single antiplatelet therapy (SAPT) for a long duration. As drug-eluting stents are frequently used in the field of coronary interventions, it has also become more difficult to terminate antiplatelet therapy compared with baremetal stents that were mainly used in the past. Aspirin is a popular antiplatelet agent administered as a SAPT after a period of DAPT. Because clopidogrel became commercially available as a relatively safe agent, thienopyridine derivatives have become the preferred SAPT choice. Additionally, it was reported that a thienopyridine derivative SAPT reduced the risk of cardiovascular events significantly compared with that of aspirin, although thienopyridine derivatives were also thought to be associated with a potential risk of bleeding complications during gastric ESD compared to aspirin [7,11-14]. However, there are no available data on safety of gastric ESD without the discontinuation of a single thienopyridine derivative agent.

Therefore, we aimed to evaluate the bleeding risks of gastric ESD without discontinuation of a single thienopyridine derivative agent in this pilot study.

\section{Patients and methods}

This study was conducted as a prospective, cohort, and observational study in 3 endoscopy centers in Japan from April 2015 to November 2016. The study was approved by the institutional review board of each center. The following institutions participated in the study: The University of Tokyo Hospital, Tokyo; New Tokyo Hospital, Chiba; Ishikawa Prefectural Central Hospital, Ishikawa. Written informed consent was obtained from each patient before the ESD procedure. This study was registered in the UMIN clinical trial registry (UMIN000017078).
Indication criteria were as follows: diagnosed as or suspicious of having gastric adenoma/adenocarcinoma; more than 6 months elapsed since the last percutaneous coronary intervention; oral administration of $75 \mathrm{mg}$ clopidogrel or $3.75 \mathrm{mg}$ prasugrel; and absence of comorbidities that associated with a tendency to bleed. The latter included hematologic disease (hemoglobin $<7.0 \mathrm{~g} / \mathrm{dL}$ or platelets $<100,000 / \mu \mathrm{L}$ ), renal disease (blood urea nitrogen $>25 \mathrm{mg} / \mathrm{dL}$ or creatinine $>2.0 \mathrm{mg} / \mathrm{dL}$ ), or liver disease (aspartate aminotransferase $>100 \mathrm{IU} / \mathrm{L}$, alanine aminotransferase $>100 \mathrm{IU} / \mathrm{L}$, or a Child-Pugh score $>6$ ). Patients with a past history of coronary stent thrombosis or those who had a stent placed in the left main coronary trunk were excluded because of risk management of perioperative re-occlusion of coronary stents, according to the consulting cardiovascular specialists. Patients administered anticoagulants were also excluded because they principally required heparin replacement as recommended in the Japan Gastroenterological Endoscopy Society (JGES) guidelines [15].

The schedule of participants is shown in $>$ Fig. 1. Aspirin and other antiplatelet agents were discontinued 5 days and 1 day before the ESD procedure, respectively, as recommended in the JGES guidelines [16]. All agents were restarted on day 14 after the ESD procedure because postoperative bleedings more than 14 days after the gastric ESD are rare. An additional reason is that a longer cessation period is not preferable to prevent re-occlusion of a coronary stent from the standpoint of cardiologists. As an acid secretion inhibitor, only oral administration of rabeprazole $10 \mathrm{mg}$ was started or switched from other acid secretion inhibitors 1 day before and continued for at least 14 days after the ESD procedure. ESD procedures were performed in the same way as other usual cases mentioned elsewhere [17]. On the first postoperative day, a second-look endoscopy was performed. Prophylactic hemostasis using hemostat forceps or clips was also performed if necessary. Oral intake was restarted on the second day after the ESD procedure. Serum hemoglobin levels were checked every day until discharge on day 6 or 7 after the ESD procedure. On day 14 after the ESD procedure, symptoms, serum hemoglobin levels, and electrocardiographic changes were checked in an outpatient 
- Table 1 Characteristics of study patients $(n=10)$.

\begin{tabular}{|l|c|}
\hline Age, mean \pm SD, years, (range) & $72.2 \pm 6.1(63-79)$ \\
\hline Sex, $\mathrm{n}$ & \multicolumn{1}{|c|}{} \\
\hline - Male & 2 \\
\hline - Female & $23.5 \pm 2.8(17.8-28.3)$ \\
\hline Body mass index, mean \pm SD, (range) & $13.2 \pm 2.1(9.5-15.6)$ \\
\hline $\begin{array}{l}\text { Serum hemoglobin, mean } \pm \text { SD, g/dL, } \\
\text { (range) }\end{array}$ & $24.3 \pm 6.4(17.5-38.3)$ \\
\hline $\begin{array}{l}\text { Number of platelets, mean } \pm \text { SD, } \\
\times 10000 / m m^{3} \text {, (range) }\end{array}$ & $100.4 \pm 6.5(92.4-118.3)$ \\
\hline $\begin{array}{l}\text { Prothrombine time, mean } \pm \text { SD, \%, } \\
\text { (range) }\end{array}$ & \\
\hline \begin{tabular}{l} 
Thienopyridine derivatives, $\mathrm{n}$ \\
\hline - Clopidogrel
\end{tabular} & 10 \\
\hline - Prasugrel & 0 \\
\hline \begin{tabular}{l} 
Aspirin / other antiplatelets, $\mathrm{n}$ \\
\hline - Aspirin
\end{tabular} & 10 \\
\hline - Other antiplatelets & Cilostazol: 1 \\
\hline
\end{tabular}

clinic. The participants were followed up for 60 days after the ESD procedure.

The primary endpoint of this study was a major adverse bleeding event associated with the ESD procedure defined as follows: requirement for an endoscopic intervention to achieve hemostasis, a blood transfusion, and/or a hemoglobin decrease $>2 \mathrm{~g} / \mathrm{dL}$ since the most recent blood test. Because there were no data available to calculate the sample size as mentioned above, we aimed to accumulate all 10 participants in a pilot study.

The exact confidence interval $(\mathrm{Cl})$ was calculated using Excel software (Microsoft Crop., Redmond, Washington, USA ).

\section{Results}

Characteristics of the 10 remaining patients are summarized in

- Table 1. They were all undergoing DAPT for a stent implantation in the coronary artery. All thienopyridine derivatives were clopidogrel. One patient was undergoing a triple antiplatelet therapy that included cilostazol.

The 10 patients underwent gastric ESD for superficial neoplasms: 3 adenomas; 5 intramucosal adenocarcinomas; and 2 invasive adenocarcinomas. Details of the ESD procedures are summarized in $>$ Table 2 . En-bloc resections and R0 resections were achieved in all cases without intraoperative bleeding complications. Among them, 2 patients required additional surgery and underwent a gastrectomy 48 days and 43 days after the ESD procedure, respectively. Unfortunately, the former patient died from a septic shock because of complications caused by the additional surgery 94 days after the ESD procedure. An autopsy proved that the cause of death was not correlated with this study. The other 8 patients underwent follow-up endosco-
- Table 2 Details of lesions and ESD procedures in 10 patients.

Lesion location, $\mathrm{n}$

\begin{tabular}{l}
\hline - Upper third \\
\hline - Middle third \\
\hline - Lower third \\
\hline - Anterior \\
\hline - Greater curvature
\end{tabular}

- Posterior 1

\begin{tabular}{l|l} 
- Lesser curvature & 4
\end{tabular}

Gross type, n

- Elevated type

2

4

- Flat type

- Depressed type

5

Electrosurgical knives, $\mathrm{n}$

- Flush knife 5

- Dual knife 3

- IT-2 knife 2

Operation time, mean \pm SD, minutes $\quad 60.1 \pm 42.8(18-173)$ (range)

Preventive treatment time, mean \pm SD, $\quad 14.2 \pm 12.8(4-43)$ minutes (range)

Number of clips, mean \pm SD (range) $\quad 3.1 \pm 2.8(0-9)$

Diameter of tumors, mean \pm SD, $\mathrm{mm} \quad 25.8 \pm 15.5(7-54)$ (range)

Diameter of resected specimen, mean $\pm S D$, mm (range)

En-bloc resection, $\mathrm{n}$

$46.1 \pm 13.3(30-75)$

$\mathrm{R} 0$ resection, $\mathrm{n}$

10

Histopathological depth of invasion

- Adenoma 3

- Intramucosal adenocarcinoma

- Invasive adenocarcinoma

2

Histopathological fibrosis

0

pies 8 weeks after the ESD procedure. All artificial ulcers were in the $\mathrm{S} 1$ stage.

Two patients experienced postoperative bleeding during the follow-up period; their characteristics are summarized in $>\mathbf{T a}$ ble 3. One patient occasionally had an oozing bleed from the artificial ulcer observed during the second-look endoscopy 1 day after the ESD procedure. Visible vessels were treated by endoscopic hemostasis and recovered well without a blood transfusion ( $\triangleright$ Fig.2). The other patient who had a tumor more than $50 \mathrm{~mm}$ in diameter experienced hematemesis and underwent endoscopic hemostasis 2 days after the ESD procedure. That patient also recovered well and did not require a 
Table 3 Details on 2 patients with major bleeding complications.

\begin{tabular}{|c|c|c|c|c|c|c|c|c|c|c|c|c|}
\hline $\begin{array}{l}\text { Case } \\
\text { no. }\end{array}$ & Age & Sex & $\begin{array}{l}\text { Co- } \\
\text { mor- } \\
\text { bidity }\end{array}$ & $\begin{array}{l}\text { Anti- } \\
\text { platelet } \\
\text { therapy }\end{array}$ & $\begin{array}{l}\text { Location } \\
\text { of lesion }\end{array}$ & $\begin{array}{l}\text { Lesion } \\
\text { size/Speci- } \\
\text { men size, } \\
\text { mm }\end{array}$ & $\begin{array}{l}\text { Opera- } \\
\text { tion } \\
\text { time, } \\
\text { min }\end{array}$ & $\begin{array}{l}\text { Preven- } \\
\text { tive } \\
\text { treat- } \\
\text { ment } \\
\text { time }\end{array}$ & $\begin{array}{l}\text { Endo- } \\
\text { scopic } \\
\text { hemas- } \\
\text { tasis }\end{array}$ & $\begin{array}{l}\text { Number } \\
\text { of pro- } \\
\text { phylactic } \\
\text { clips }\end{array}$ & $\begin{array}{l}\text { Blood } \\
\text { transfu- } \\
\text { sion }\end{array}$ & $\begin{array}{l}\text { Maximum } \\
\text { decrease of } \\
\text { hemoglobin } \\
\text { level, g/dL }\end{array}$ \\
\hline 1 & 63 & M & IHD & $\begin{array}{l}\text { DAPT } \\
\text { (clopi- } \\
\text { dogrel) }\end{array}$ & $\begin{array}{l}\text { Lower } \\
\text { third } \\
\text { Greater } \\
\text { curva- } \\
\text { ture }\end{array}$ & $12 / 40$ & 18 & 8 & Day 1 & 0 & No & -4.0 \\
\hline 2 & 73 & $M$ & IHD & $\begin{array}{l}\text { DAPT } \\
\text { (clopi- } \\
\text { dogrel) }\end{array}$ & $\begin{array}{l}\text { Middle } \\
\text { third } \\
\text { Lesser } \\
\text { curva- } \\
\text { ture }\end{array}$ & $54 / 75$ & 77 & 35 & Day 2 & 5 & No & -3.1 \\
\hline
\end{tabular}
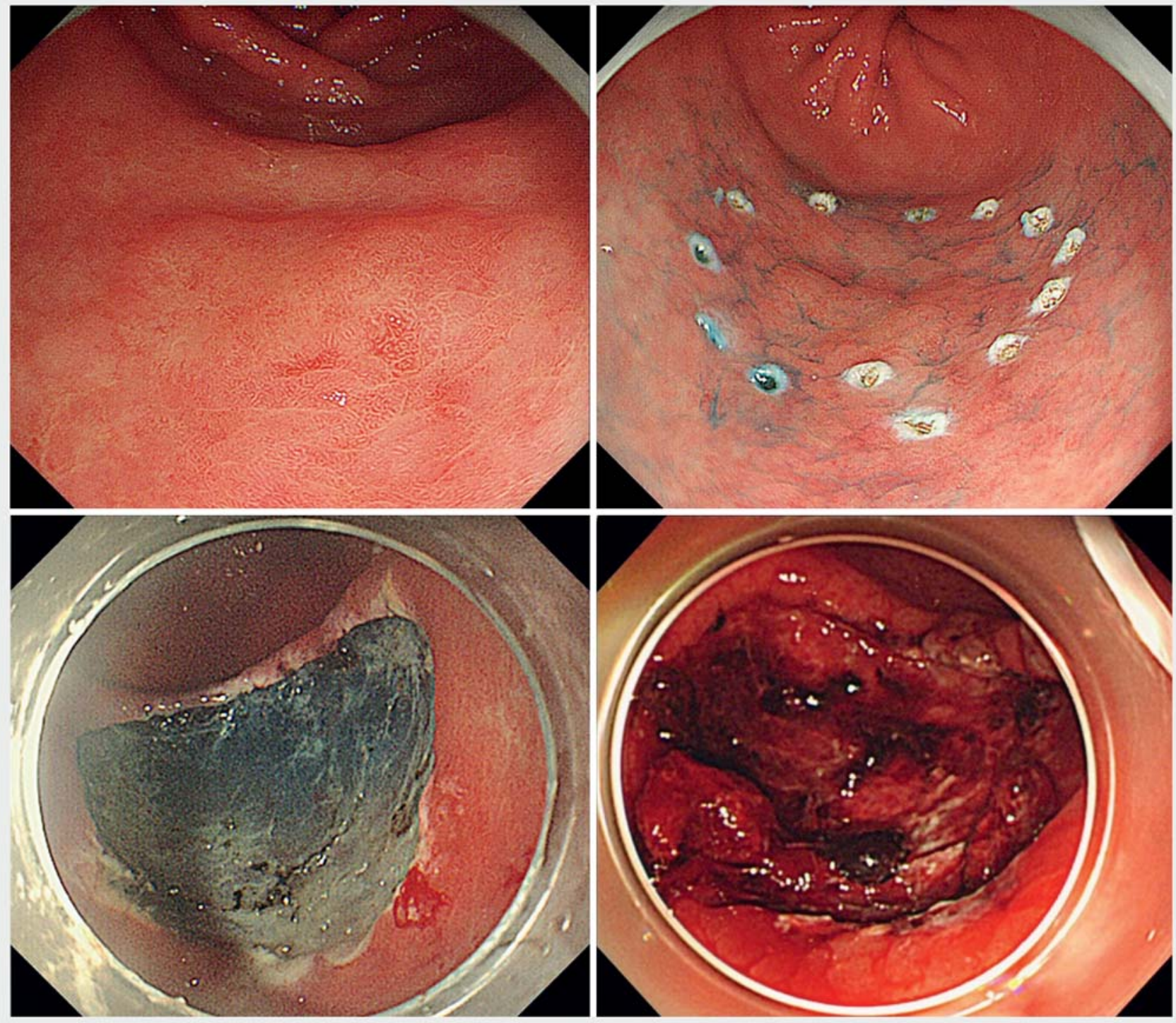

- Fig. 2 Endoscopic images from Case 1. A flat elevated lesion $12 \mathrm{~mm}$ in diameter was located in the greater curvature of the lower third of the stomach (upper left and right). Although no visible vessels were observed in the artificial ulcer (lower left), postoperative bleeding was observed on second-look endoscopy the day after ESD (lower right). 

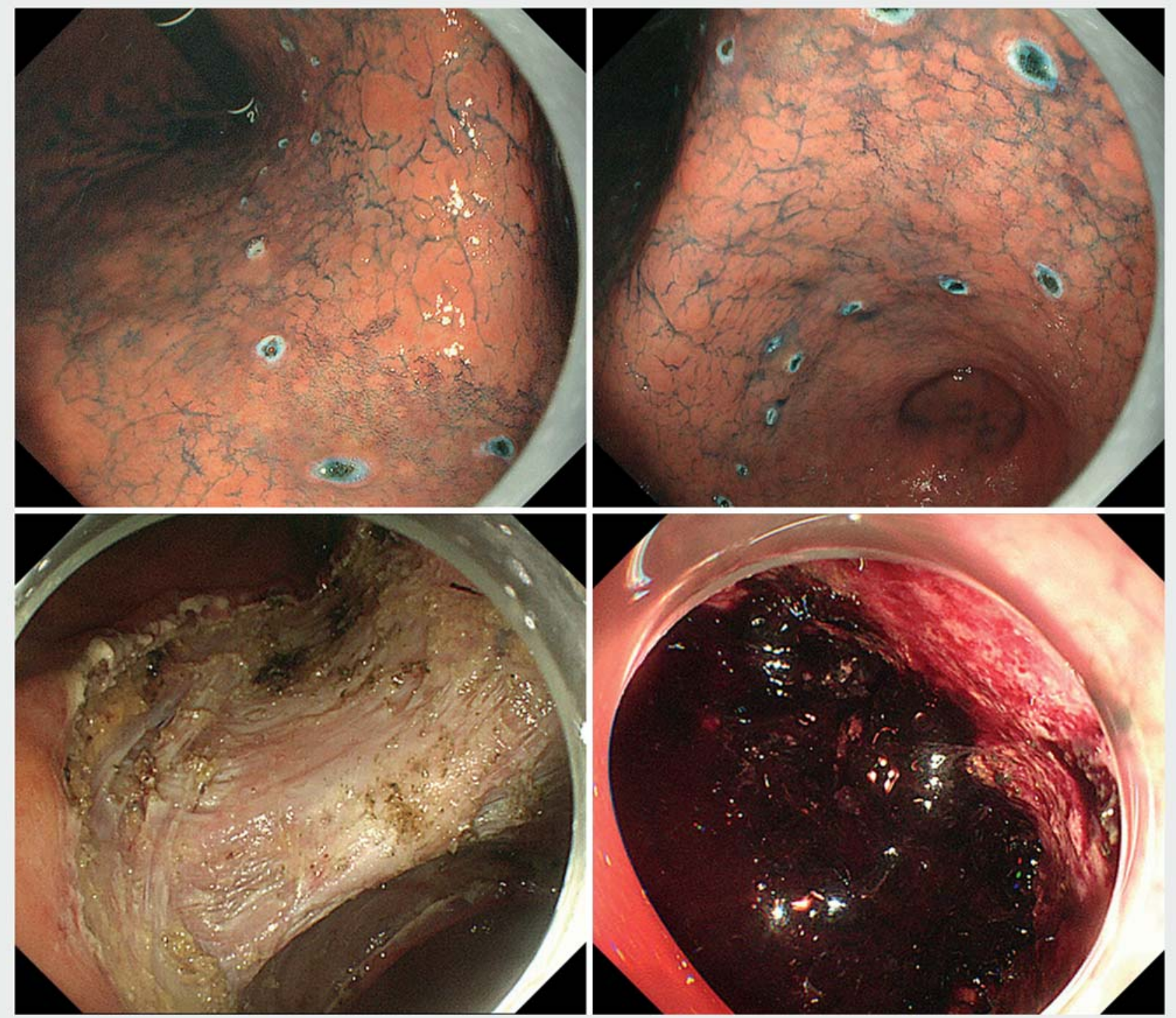

- Fig. 3 Endoscopic images from Case 2. A flat elevated lesion $54 \mathrm{~mm}$ in diameter was located in the lesser curvature of the middle third of the stomach (upper left and right). The artificial ulcer after ESD was approximately $70 \mathrm{~mm}$ in diameter (lower left). This patient experienced hematemesis from the visible vessel in the artificial ulcer observed on urgent endoscopy (lower right).

blood transfusion ( $>$ Fig.3). No patients experienced thromboembolic events including stent re-occlusions in the followup period.

\section{Discussion}

Thienopyridine derivatives are thought to be a potential risk factor for postoperative bleeding after gastric ESD [7, 11]. We also reported previously that thienopyridine derivatives might be a risk factor for postoperative bleeding after gastric ESD without discontinuation of a single agent of aspirin [7]. However, in our previous report, all postoperative bleeding occurred after re-starting thienopyridine derivatives in patients undergoing DAPT. Combined use of antithrombotic agents is known to increase risk of gastrointestinal bleeding compared to use of a single antithrombotic agent. Hallas et al. [17] reported that the odds ratio of gastrointestinal bleeding with combined use of aspirin and clopidogrel was 7.4 (95\% Cl: $3.5-15)$ although that for aspirin alone was 1.8 (95\% Cl: $1.5-2.1)$. However, they also reported that the odds ratio for gastrointestinal bleeding with clopidogrel alone was 1.1 (95\% Cl: $0.6-2.1)$. Discontinuing aspirin in patients undergoing triple antithrombotic DAPT and an anticoagulant was reported to reduce risk of gastrointestinal bleeding significantly in a randomized controlled trial [18]. Thus, periendoscopic discontinuation of aspirin can be an option for patients undergoing DAPT considering the risks of bleeding and stent re-occlusion. However, there are no data on the impact of a single thienopyridine derivative agent on gastric ESD. This is the first report to evaluate the feasibility 
of gastric ESD without discontinuation of a single thienopyridine derivative agent.

In this study, the rate of postoperative bleeding seemed to be higher than that in gastric ESD without use of antithrombotic agents, although the number of patients was too small to identify a statistically significant risk factor of postoperative bleeding. In addition, 1 patient with postoperative bleeding had a tumor more than $50 \mathrm{~mm}$ in diameter that was reported to be a solid risk factor for postoperative bleeding after gastric ESD [19]. Therefore, in a larger-scale clinical trial in an appropriate setting, in which known risk factors are well-controlled, the rate of postoperative bleeding may be quite different from that reported in this study.

It is notable, however, that 8 of the 10 patients underwent gastric ESD without major bleeding complications. The prophylactic treatments used for postoperative bleeding in this study are all current standard treatments in clinical practice. Nowadays, there are novel treatments to prevent postoperative bleeding after gastric ESD. A polyglycolic acid sheet is one promising treatment to shield artificial ulcers and prevent postoperative bleeding $[20,21]$. Vonoprazan is a novel and strong acid secretion inhibitor categorized as a potassium-competitive acid blocker. It is reported to remarkably reduce the postoperative bleeding rate to $1.3 \%$ and induce postoperative artificial ulcer healing after gastric ESD $[22,23]$. Combining these emerging prophylactics might provide a safe option for patients administered antithrombotic agents, including those who undergo gastric ESD without discontinuing a single thienopyridine derivative agent.

Undoubtedly, the limitations of this study were the very small number of patients enrolled and the pilot study design. Because of this, it was difficult to analyze risk factors for postoperative bleeding after gastric ESD without discontinuing a single thienopyridine derivative agent. However, this study demonstrated that such gastric ESD is not necessarily impossible, as mentioned above. Considering the severity of an ischemic heart event due to re-occlusion of a coronary stent during cessation of thienopyridine derivatives, gastric ESD without discontinuing a single thienopyridine derivative agent might be controllable by careful observation and using upcoming preventive treatments for postoperative bleeding.

\section{Conclusion}

In conclusion, the postoperative bleeding rate tended to be higher in gastric ESD with continuation of a single thienopyridine derivative agent although en-bloc resections were possible. Additional preventive measures are mandatory to carry out safe gastric ESD in such settings.

\section{Acknowledgments}

Grant-in-Aid for Young Scientists (B) from the Ministry of Education, Culture, Sports, Science and Technology (MEXT).

The authors are grateful to Dr. Noboru Kawata, Dr. Kohei Takizawa, Dr. Naomi Kakushima, Dr. Hiroyuki Ono, Dr. Naoki Kawai, Dr Toshiyuki Yoshio, Dr. Yorimasa Yamamoto, Prof. Shigetaka
Tounou, and Prof. Tomoki Michida for their valuable comments and suggestions about carrying out this study. This work was supported in part by Grant-in-Aid for Young Scientists (B) from the Ministry of Education, Culture, Sports, Science and Technology (MEXT).

\section{Competing interests}

None

References

[1] Uedo N, Takeuchi Y, Ishihara R. Endoscopic management of early gastric cancer: endoscopic mucosal resection or endoscopic submucosal dissection: data from a Japanese high-volume center and literature review. Ann Gastroenterol 2012; 25: 281 - 290

[2] Gotoda T, Ho KY, Soetikno R et al. Gastric ESD: current status and future directions of devices and training. Gastrointest Endosc Clin N Am 2014; 24: $213-233$

[3] Saito Y, Sakamoto T, Nakajima T et al. Colorectal ESD: current indications and latest technical advances. Gastrointest Endosc Clin N Am 2014; 24: $245-255$

[4] Oda I, Suzuki H, Nonaka $\mathrm{S}$ et al. Complications of gastric endoscopic submucosal dissection. Dig Endosc 2013; 25: 71 - 78

[5] Saito I, Tsuji Y, Sakaguchi Y et al. Complications related to gastric endoscopic submucosal dissection and their managements. Clin Endosc 2014; 47: $398-403$

[6] Ono S, Fujishiro M, Hirano K et al. Retrospective analysis on the management of anticoagulants and antiplatelet agents for scheduled endoscopy. J Gastroenterol 2009; 44: 1185-1189

[7] Ono S, Fujishiro M, Yoshida $\mathrm{N}$ et al. Thienopyridine derivatives as risk factors for bleeding following high risk endoscopic treatments: Safe Treatment on Antiplatelets (STRAP) study. Endoscopy 2015; 47: 632 637

[8] Antiplatelet Trialists' Collaboration. Collaborative overview of randomised trials of antiplatelet therapy-I: Prevention of death, myocardial infarction, and stroke by prolonged antiplatelet therapy in various categories of patients. BMJ 1994; 308: 81-106

[9] Meschia JF, Bushnell C, Boden-Albala B et al. Guidelines for the primary prevention of stroke: a statement for healthcare professionals from the American Heart Association/American Stroke Association. Stroke 2014; 45: 3754 - 3832

[10] Grines CL, Bonow RO, Casey DE et al. Prevention of premature discontinuation of dual antiplatelet therapy in patients with coronary artery stents: a science advisory from the American Heart Association, American College of Cardiology, Society for Cardiovascular Angiography and Interventions, American College of Surgeons, and American Dental Association, with representation from the American College of Physicians. Circulation 2007; 115: 813-818

[11] Hayashi T, Doyama H, Takemura K et al. Evaluation of the risk and timing of bleeding after gastric endoscopic submucosal dissection with different antithrombotic therapies. Gastroenterol Endosc [article in Japanese] 2013; 55: $1806-1811$

[12] Park TK, Song YB, Ahn J et al. Clopidogrel versus aspirin as an antiplatelet monotherapy after 12-month dual-antiplatelet therapy in the era of drug-eluting stents. Circ Cardiovasc Interv 2016; 9: e002816 doi:10.1161/CIRCINTERVENTIONS.115.002816

[13] Tounou S, Morita Y. Gastric and duodenal endoscopic submucosal dissection in patients on aspirin therapy has increased risk of hemor- 
rhage but is feasible. Gastroenterol Endosc [article in Japanese] 2011; 53: $3326-3335$

[14] Sanomura Y, Oka S, Tanaka S et al. Continued use of low-dose aspirin does not increase the risk of bleeding during or after endoscopic submucosal dissection for early gastric cancer. Gastric Cancer 2014; 17: $489-496$

[15] Fujimoto K, Fujishiro M, Kato M et al. Guidelines for gastroenterological endoscopy in patients undergoing antithrombotic treatment. Dig Endosc 2014; 26: 1 - 14

[16] Goto O, Fujishiro M, Kodashima S et al. Outcomes of endoscopic submucosal dissection for early gastric cancer with special reference to validation for curability criteria. Endoscopy 2009; 41: 118-122

[17] Hallas J, Dall M, Andries A et al. Use of single and combined antithrombotic therapy and risk of serious upper gastrointestinal bleeding: population based case-control study. BMJ 2006; 333 : 726

[18] Dewilde WJ, Oirbans T, Verheugt FW et al. Use of clopidogrel with or without aspirin in patients taking oral anticoagulant therapy and undergoing percutaneous coronary intervention: an open-label, randomised, controlled trial. Lancet 2013; 381: 1107-1115
[19] Jeong $\mathrm{HK}$, Park $\mathrm{CH}$, Jun $\mathrm{CH}$ et al. A prospective randomized trial of either famotidine or pantoprazole for the prevention of bleeding after endoscopic submucosal dissection. J Korean Med Sci 2007; 22: 1055 1059

[20] Takimoto K, Toyonaga T, Matsuyama K. Endoscopic tissue shielding to prevent delayed perforation associated with endoscopic submucosal dissection for duodenal neoplasms. Endoscopy 2012; 44: (Suppl. 02): UCTN: E414-415

[21] Tsuji Y, Ohata K, Gunji T et al. Endoscopic tissue shielding method with polyglycolic acid sheets and fibrin glue to cover wounds after colorectal endoscopic submucosal dissection (with video). Gastrointest Endosc 2014; 79: 151 - 155

[22] Kagawa T, Iwamuro M, Ishikawa S et al. Vonoprazan prevents bleeding from endoscopic submucosal dissection-induced gastric ulcers. Aliment Pharmacol Ther 2016; 44: 583-591

[23] Maruoka D, Arai M, Kasamatsu S et al. Vonoprazan is superior to proton pump inhibitors in healing artificial ulcers of the stomach postendoscopic submucosal dissection: A propensity score-matching analysis. Dig Endosc 2017; 29: 57 - 64 